\title{
Does cyst growth predict malignancy in branch duct intraductal papillary mucinous neoplasms? Results of a large multicenter experience
}

Abdul El Chafic, MD ${ }^{1,2,3 \#}$, Ihab I. El Hajj, MD, MPH ${ }^{1,4 \#}$, John DeWitt, MD ${ }^{1}$, C. Max Schmidt, MD, PhD ${ }^{5}$ Ali Siddiqui, MD², Stuart Sherman, MD ${ }^{1}$, Ashish Aggarwal, $\mathrm{MBBS}^{6}$, Mohammad Al-Haddad, MD, MSc ${ }^{1 *}$

${ }^{\#}$ Both authors share co-first authorship.

${ }^{1}$ Division of Gastroenterology, Indiana University School of Medicine, Indianapolis, Indiana, USA

${ }^{2}$ Division of Gastroenterology, Thomas Jefferson University, Philadelphia, Pennsylvania, USA

${ }^{3}$ Division of Gastroenterology, Ochsner Health System, New Orleans, Louisiana, USA

${ }^{4}$ Division of Gastroenterology, Saint George Hospital University Medical Center, Balamand University, Beirut, Lebanon

${ }^{5}$ Department of Surgery, Indiana University Pancreatic Cyst and Cancer Early Detection Center, Indiana University School of Medicine, Indianapolis, Indiana, USA

${ }^{6}$ Community Health Network, Indianapolis, Indiana, USA

\section{* Corresponding author:}

Mohammad Al-Haddad, MD, MSc, FASGE

Associate Professor of Medicine

Department of Medicine,

Division of Gastroenterology and Hepatology, 
Indiana University School of Medicine,

550 N. University Blvd, Suite 4100

Indianapolis, IN 46202

Phone: 317-944-7896

Fax: 317.948.8144

Email: $\underline{\text { moalhadd@iu.edu }}$

\section{ABSTRACT}

Background: Cyst growth of BD-IPMNs on follow-up imaging remains a concerning sign.

Aims: To describe cyst size changes over time in BD-IPMNs, and determine whether cyst growth rate is associated with increased risk of malignancy.

Methods: This is a retrospective study performed at two high volume tertiary centers. Mean cyst size at baseline (MCSB) and mean growth rate percentage (MGRP) were calculated. Rapid cyst growth was defined as MGRP $\geq 30 \% /$ year. Patient and cyst related characteristics were studied.

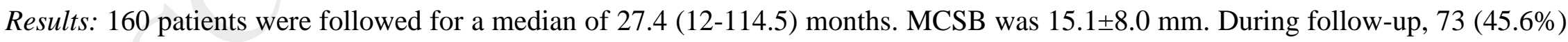
showed any cyst size increase, of which 15 cysts $(9.4 \%)$ exhibited MGRP $\geq 30 \%$ /year. Rapid cyst growth was not associated with patient or cyst characteristics. Cyst fluid molecular analysis from 101 cysts showed KRAS mutation in 26. Compared to KRASnegative cysts, neither MCSB (16.0 mm vs. $17.7 \mathrm{~mm}$; p=0.3) nor MGRP (3.9\%/year vs. 5.8\%/year; $\mathrm{p}=0.7)$ was significantly different. 
Eighteen patients underwent surgery; 15 (83\%) had LGD, and 3 had advanced neoplasia. Two cysts with LGD and one cyst with advanced neoplasia had MGRP $\geq 30 \% /$ year.

Conclusion: Increase in BD-IPMNs size was not associated with the known high risk patient or cyst-related characteristics. Rapid growth of BD-IPMNs was not associated with advanced neoplasia on surgical pathology.

Keywords: branch-duct IPMN (BD-IPMN); endoscopic ultrasound; cyst growth rate; CT; MRI; molecular analysis; Dysplasia; neoplasia

\section{Introduction}

Branch-duct intraductal papillary mucinous neoplasms (BD-IPMNs) are the most common variant of IPMNs and are most often detected incidentally in patients undergoing abdominal imaging. Fortunately, the majority of incidental BD-IPMNs are low risk lesions where management has evolved to become more conservative in the recent years. According to the 2017 revised International consensus guidelines (ICG) for the management of IPMNs [1], the indications for surgical resection include main-duct IPMNs (MDIPMNs) and BD-IPMNs with high risk stigmata. Cyst size exceeding $3 \mathrm{~cm}$ is no longer an indication for resection as initially proposed in the 2006 ICG [2], and a rapidly increasing cyst size (> 5mm/2years) is proposed as a new high risk factor for malignancy based on earlier studies [1]. 
Similarly, the American Gastroenterological Association (AGA) guidelines on the diagnosis and management of asymptomatic neoplastic pancreatic cysts recommend that patients with both a solid component and a dilated pancreatic duct (PD) and/or concerning features on endoscopic ultrasound (EUS)-fine-needle aspiration FNA) should undergo surgery to reduce the risk of mortality from carcinoma [3]. Although previous studies endorsed rapid cyst growth as a high risk feature and recommended resection be considered for these lesions [4,5], the AGA guidelines suggest that an increase in cyst size alone should not be considered a significant risk factor for malignancy [6]. The validity of cyst size alone in predicting malignancy has been scrutinized by recent studies; the results of which were controversial $[7,8]$.

The aims of this study were to describe cyst size changes over time in patients with BD-IPMNs, and to determine whether cyst growth rate can be associated with risk of malignancy in a multicenter setting.

\section{Materials and Methods}

\subsection{Study Population}

This is a retrospective study performed at two high volume tertiary centers. Using our prospectively maintained EUS database, we identified all patients with a diagnosis of a BD-IPMN at Indiana University Hospital (IUH) and Thomas Jefferson University (TJU) between January 2001 and December 2013. Patients were included if they were followed for at least 12 months and underwent crosssectional imaging (CT scan or MRI/MRCP) at least twice during the follow-up period. In patients only surveyed by imaging, the diagnosis of BD-IPMN was established by EUS with/without FNA confirming one or more dilated branch ducts communicating with 
the MPD, and/or cytology consistent with mucinous pathology and/or carcinoembryonic antigen (CEA) > $192 \mathrm{ng} / \mathrm{ml}$ [9]. If cyst fluid molecular analysis was performed, the presence of a K-ras point mutation was considered sufficient for the diagnosis of a BD-IPMN lesion when ductal communication was present [10]. Surgical pathology was the reference standard in patients who underwent surgery. Patients found to have concomitant main pancreatic duct (MPD) involvement on imaging or resection pathology were excluded. Based on pathology, noninvasive IPMNs were subcategorized into low-grade or high-grade dysplasia, based on the maximal degree of dysplasia in the lining epithelium. Invasive IPMNs were subcategorized into minimally or grossly invasive lesions. To simplify study outcomes, BD-IPMNs were further classified into benign (low- or moderate-grade dysplasia) or malignant tumors (high-grade dysplasia or invasive cancer) based on the World Health Organization (WHO) classification [11]. Patients' medical records were reviewed to obtain demographic data, clinical presentation, medical history, family history, social history, cysts characteristics by cross-sectional imaging and/or EUS. The study period was defined as the interval between the index imaging (initial diagnosis) and the most recent available imaging and clinical follow-up, with an attempt to obtain a minimum of 12-month follow-up with 2 or more serial imaging. Surgical pathology results were documented in patients who underwent surgery. Long-term clinical follow-up after the index imaging was obtained by review of the medical records and all available serial imaging. Patient-specific factors such as smoking, alcohol consumption, cyst-related symptoms, and family history of pancreatic cancer were collected. Cystrelated characteristics such as location, multiplicity, presence of septations or nodules, cyst fluid CEA and molecular analysis results were recorded. The study protocol was approved by the Institutional Review Board of the two respective institutions. 


\subsection{Cyst size measurement}

Based on the 2017 revised ICG, cyst size calculations were based on contrast enhanced CT or gadolinium-enhanced MRI [1]. If a patient had both CT and MRI performed over multiple points of time, we adopted only one of them over the follow-up period to minimize measurement variation between different imaging modalities. Since most cysts were not exactly spherical, cyst "size" on imaging studies was calculated by averaging the major and minor axis dimensions. This includes the sum of maximum dimensions in multiloculated lesions. For multifocal lesions, the largest cyst only was included in the study. After obtaining imaging data, cyst growth $(\mathrm{mm})$ was calculated by final cyst size $(\mathrm{mm})$ - initial cyst size (mm). Mean growth rate (MGR) was calculated as cyst growth per year. Mean cyst growth rate percentage (MGRP) per year was calculated as a percentage from the following formula which takes into account baseline cyst size and time during which the cyst growth occurred:

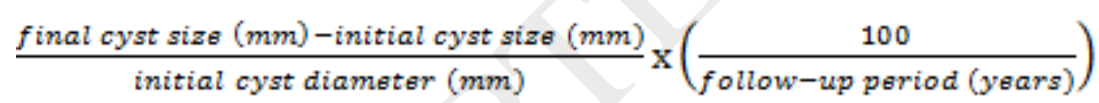

Rapid cyst growth was defined as a mean MGRP $\geq 30 \% /$ year based on a previously published study by Kang et al where he found that malignant BD-IPMN grew significantly faster than benign BD-IPMN with a mean annual percentage of cyst growth rate of 29.6 $\% / y e a r$ [4].

\subsection{Cyst fluid analysis}


EUS +/- FNA was performed in all patients. All EUS-FNA procedures were performed by one of six experienced endosonographers. The following cyst characteristics were recorded: cyst location, MPD diameter and communication, septations, cyst wall thickness, calcifications, presence of mural nodules and associated solid mass. EUS was performed using linear echoendoscopes (32UA or 32 UX, Pentax Medical Co, Montvale, NJ; GF-UC30P or GF-UC140P, Olympus America, Inc., Center Valley, PA) with or without radial echoendoscopes (GF-UM20, GF-UM130, or GF-UM160, Olympus America, Inc., Center Valley, PA). FNA was performed using 19-, 22- or 25-gauge needles with the presence of on-site cytopathology. The aspirated fluid was processed on site for cytology slides. Allocation of cyst fluid for CEA, or molecular analysis was performed at the discretion of the endosonographer based on the volume obtained. Molecular analysis of cyst fluid, if performed (carried out by the former PathFinderTG/Pancreas; RedPath Integrated Pathology, Inc., Pittsburgh, Pennsylvania, USA, and currently Interpace Diagnostics), included DNA quantity and quality, KRAS point mutation, and tumor suppressor genes (loss of heterozygosity -LOH) [12].

\subsection{Surgical indications}

Surgical resection was recommended if patients developed symptoms related to the cysts, or in the presence of suspicious features on imaging and/or EUS-FNA, and if patients were fit for surgery. For BD-IPMNs diagnosed before 2006, suspicious features for malignancy included cyst size $\geq 3 \mathrm{~cm}$, MPD dilation $(\geq 10 \mathrm{~mm})$, presence of solid component, cytologic evidence of high-grade dysplasia, or positive cytology for malignancy. For BD-IPMNs diagnosed between 2006 and 2013, suspicious features for malignancy 
were based on the 2006 ICG and the 2012 ICG [2,13]. For asymptomatic patients, imaging surveillance with EUS and CT/MRI was considered every 3-12 months based on the baseline findings on index imaging.

\subsection{Statistical Analysis}

Statistical analysis was performed using SPSS 21.0 for Windows software (SPSS, Chicago, IL, USA). Continuous variables were reported as mean \pm standard deviation $(\mathrm{SD})$. Categorical variables were presented as numbers and percentages. The Student's t-test was performed for continuous variables and chi-square or Fisher's exact test for categorical variables. Linear regression was used to estimate correlation between baseline cyst size and MGRP. A p value < 0.05 was considered statistically significant.

\section{Results}

Between January 2001 and December 2013, 287 patients with pure BD-IPMNs were identified from the IUH database and 87 patients from the TJU database (Fig. 1). One hundred sixty six patients from the first database and 48 patients from the second database, with follow-up less than 12 months or fewer than 2 serial imaging studies, were excluded. One hundred and sixty patients met the study criteria and were included in the analysis.

\subsection{Patient and Cyst characteristics}


Patients' characteristics are summarized in Table 1. Sixty four patients (40\%) were males. The mean age was $64.6 \pm 12.0$ years. The median follow-up was 27.4 (range, 12-114.5) months. MRI/MRCP was the most commonly performed index and surveillance imaging study (230) followed by EUS (75) then CT (68). All patients underwent EUS either at baseline or during follow-up most of which underwent FNA (153/160). Molecular analysis was performed in 101 (63.1\%) patients.

Cysts' characteristics are summarized in Table 2. Eighteen patients underwent surgery during follow up of whom 15 (83) had low grade dysplasia (LGD), and 3 had advanced neoplasia (1 high grade dysplasia and 2 with invasive carcinoma) on pathology.

The mean cyst size at baseline (MCSB) was $15.1 \pm 8.0 \mathrm{~mm}$. The mean cyst growth rate (MGR) was $0.58 \pm 4.33 \mathrm{~mm} / \mathrm{year}$. The mean growth rate percentage (MGRP) was $5.68 \pm 24.89 \%$ year. Seventy three $(45.6 \%)$ patients had cyst size increase of a minimum of 1 mm, of whom $15(9.4 \%)$ patients had a MGRP $\geq 30 \%$ /year occurring more in older patients (70.8 vs. 64.1 years; p=0.03). Eighty seven patients (54.4\%) did not have cyst size increase (Table 3). The distribution of number of cysts by the percentage of MPGR is illustrated in Figure 2.

Cyst characteristics and surgical status according to follow up duration are summarized in Table 4. Cysts growing rapidly were found to be followed for a shorter duration of time.

\subsection{Correlation between MGR, MGRP and Patient and Cyst Characteristics}


Rapid cyst growth did not correlate with patient-specific factors such as smoking, alcohol consumption, development of interval symptoms, or family history of pancreatic cancer. Rapid cyst growth did not correlate with cyst characteristics such as number (unifocal vs multifocal), presence of septations or nodules, cyst fluid CEA level > $192 \mathrm{ng} / \mathrm{ml}$, and molecular analysis results (Table 5). As noted above, cyst fluid from 107 patients was sent for DNA analysis and showed KRAS mutation in 27. Compared to KRASnegative cysts, neither MCSB (16.0 mm vs $17.7 \mathrm{~mm}$; p=0.3) nor MGRP (3.9\%/year vs 5.8\%/year; p=0.7) was significantly different. Similar observations were found in cysts with high DNA content ( $\geq 40 \mathrm{ng} / \mathrm{ul})$, good quality DNA or $\geq 2$ allelic imbalance (LOH) mutations. Rapid cyst growth (MGRP $\geq 30 \%$ /year) was similar between the surgical and non-surgical groups (16.7\% vs $8.5 \%$; $\mathrm{p}=0.26$ ). Only one of the 3 patients with rapid cyst growth in the surgical group had invasive carcinoma on pathology, while the other 2 had LGD. MCSB was not statistically different in the surgical group compared to the non-surgical group (17.5 vs. 14.7; $p=0.29)$ and in the advanced neoplasia subgroup compared to those with low-grade dysplasia (20.0 vs. 17.07; $\mathrm{p}=0.67)$. Cysts growing $\geq 2 \mathrm{~mm} / \mathrm{year}$ but not with MGPR $\geq 30 \% /$ year were resected more often than those that regressed or grew at a slower rate $(32.3 \%$ vs $6.2 \%$; $<0.001)$

(Table 5). Otherwise cysts growing $\geq 2 \mathrm{~mm} /$ year behaved similar to those with MGPR $\geq 30 \% /$ year with respect to correlation with significant patient or cyst characteristics. Linear regression showed that smaller cysts did not grow at a faster rate $\left(\mathrm{R}^{2}=2 \%\right.$; $\left.=0.07\right)$ compared to larger ones (Fig. 3). 


\section{Discussion}

Over the past 2 decades, pancreas cyst detection has increased secondary to an aging population, advancements in imaging technology and their overutilization for a variety of health-related purposes. This led to a flurry of incidental pancreatic lesions detected, the vast majority of which are low risk but result in subjecting patients to prolonged imaging surveillance. In the absence of reliable cyst fluid biomarkers or accurate imaging predictors of malignancy, consensus statements and societal guidelines have been developed to address management of pancreatic cysts neoplasms [14]. The approach to pancreatic cysts has changed over the last decade in regards to the utilization of EUS-FNA. The 2005 ASGE guidelines, for example, recommended EUS-FNA of all cysts for cyst fluid analysis and cytology [15]. The 2006 ICG on the other hand called for more selective use of EUS based on cyst size and presence of worrisome features in IPMNs and MCNs [2]. The 2015 AGA guidelines for asymptomatic cysts recommended EUS examination only in the presence of 2 high-risk stigmata (cyst size $\geq 30 \mathrm{~mm}$, dilated MPD, solid component), and surgical referral in the presence of malignant cytology on EUS-FNA or at least 2 high-risk features (cyst size $\geq 30 \mathrm{~mm}$, dilated MPD, solid component) [16]. The 2012 ICG and the 2017 revised ICG similarly recommended EUS for the evaluation of worrisome features but cyst size alone became less of a concern $[1,13]$. This reflects better understanding of the natural history of pancreatic cysts in general, and clearly elevated the threshold for EUS-guided sampling or surgical resection, shifting management paradigms towards more conservative strategies. Accordingly, magnetic resonance imaging (MRI) is increasingly recommended for periodic surveillance to avoid excessive radiation exposure during CT examinations. 
The guidelines, however, did not clearly address lesions that continue to grow slowly or grow considerably in a short time to identify a threshold to repeat EUS sampling or surgical resection during surveillance of such lesions. This continues to be a dilemma to many clinicians due to long-term cost implications of intensive imaging surveillance, or the morbidity related to surgical resection. Most recently the revised ICG 2017 guidelines defined rapid cyst growth as growth of > $5 \mathrm{~mm} / 2$ years and considered this to be a worrisome feature that requires shorter interval surveillance [1]. It is worth noting that the definition of rapid cyst growth was based on few retrospective series $[4,5,17,18]$ with different definitions of rapid cyst growth and conflicting data around the correlation between cyst growth and the grade of dysplasia in the lesion (Table 6). Interpretation of the results of such series is also limited by the relatively short duration of follow-up and the small number of patients. Also the definition of rapid cyst growth as $>5 \mathrm{~mm} / 2$ years does not account for baseline cyst size which in our opinion should weigh in the value of rapid cyst growth. Our study adds to existing literature on this topic and summarizes our multicenter experience in managing pancreatic cysts that grow over time in the context of specialized multi-disciplinary pancreas cyst programs.

Natural history of IPMN is increasingly described in literature. Review of 4 series $[4,19-21]$ on BD-IPMNs showed an overall increase in cyst size in $2-10 \%$ and invasive cancer rates of up to $6.3 \%$. Similarly, Woo et al. [17], in a single center study on 190 patients with BDIPMNs, noted an increase in cyst size in $11(10.5 \%)$ of 105 patients followed without surgery, and invasive cancer in $1(0.8 \%)$ of 124 patients initially managed conservatively. Authors concluded that a simple increase in cyst size in the absence of suspicious features on imaging during follow-up is not a reliable predictor of malignancy in BD-IPMN. On the other hand, Yamaguchi et al. [22] showed that an increase in the BD diameter was significantly associated with invasive cancer compared with carcinoma in situ. An 
increase in cyst size of $11.3 \mathrm{~mm} / \mathrm{year}$, by periodic transabdominal ultrasonography, was a discriminating factor between benign and malignant BD-IPMNs with $81 \%$ accuracy. In a retrospective study of 121 patients with BD-IPMNs, Rautou et al. [5] concluded that the only factor associated with signs of progression to malignancy was an increase in cyst size to more than $5 \mathrm{~mm}$ during the followup evaluation regardless of baseline cyst size and duration of follow up, with a 5 -year cumulative risk of $38 \%$ vs. $8 \%$ ( $\mathrm{p}=.003$ ). Two years later, researchers from the same institution followed the natural history of BD-IPMN using serial CT scan and surgical pathology from 201 patients with BD-IPMNs [4]. Cyst growth rate $\geq 2 \mathrm{~mm} /$ year had 3- and 5-year cumulative risks of malignancy of $6.4 \%$ and $45.5 \%$; whereas cyst growth rate $<2 \mathrm{~mm} /$ year had corresponding risks of $1.8 \%$ and $1.8 \%$ respectively (p $<.001$ ). More recently, Kwong et al. [18] further studied the clinical implications of cyst growth rate in a retrospective multicenter study of 284 patients with BD-IPMNs. All patients underwent EUS evaluation followed by surveillance imaging. Cyst growth rate between 2 and $5 \mathrm{~mm} /$ year was associated with an increased risk of malignancy with hazard ratio (HR) of 11.4 when compared to subjects with cyst growth $<2 \mathrm{~mm} /$ year $(\mathrm{p}=.0004)$. Cyst growth $\geq 2 \mathrm{~mm} /$ year had a sensitivity of $78 \%$, specificity of $90 \%$, and accuracy of $88 \%$ to identify malignancy. Total cyst growth $\geq 10 \mathrm{~mm}$ had a sensitivity of $100 \%$, specificity of $95 \%$, and accuracy of $88 \%$ to identify malignancy. Using percentage growth (total growth/initial size) to assess the presence of malignancy produced an area under ROC curve of 0.91 . The optimal cutoff was $40 \%$ BD-IPMN growth, which produced a sensitivity, specificity, and accuracy of 78,84 , and $84 \%$ respectively. However, surveillance was not standardized as this was a retrospective study across 4 centers. Follow-up imaging was generally recommended on at least a yearly basis, though patients and referring physicians did not necessarily adhere to these recommendations. Besides, this study (and all the above-mentioned studies) used CT, MRI/MRCP, and/or EUS interchangeably as 
means of imaging surveillance without committing to a single modality per patient over time. Considerable variation in size estimates (3 to $4 \mathrm{~mm}$ ) of pancreatic cysts by different imaging modalities (CT, MRCP, EUS) has been previously described [23]. Attempts to detect a 2-mm difference on imaging are vulnerable to human errors in measurement, measurement of the cyst at different crosssections, and variability inherent to the physical features of the imaging modalities. This should be taken into account when making management decisions. Therefore, the use of a single imaging modality is recommended during follow-up, and a high specificity should be sought when evaluating BD-IPMN for malignancy to avoid unnecessary resections. In our study, we took into consideration the above-mentioned limitations and adopted the same imaging modality for follow-up to avoid the variation is size estimates.

In our study, we further evaluated the significance of cyst growth using a mean cyst growth rate percentage (MGRP). We believe that growth rate should be reflected as a proportion averaged over the number of years the cyst is surveyed (\%/year) to account for baseline cyst size and hedge against year-to-year size fluctuations. We chose an MGRP cutoff of $\geq 30 \% /$ year to be significant [5]. Our study shows that a MGR $\geq 2 \mathrm{~mm} /$ year or MGRP $\geq 30 \%$ /year was not associated with known high risk patient or cyst characteristics. More importantly, there was no association between MGPR and tumor markers or degree of dysplasia on surgical pathology, in contrast to some of the studies discussed above $[4,5,18]$. We believe that our definition of "rapid cyst growth" factors in longer term observations along with a more complete account of patient and cyst characteristics.

Similar to previous studies, we showed that any cyst size increase over time is rather common; occurring in more than $40 \%$ of patients with BD-IPMNs, fifth of whom had significant growth. We could not reproduce the previous observation that small cysts grew at a faster rate than larger ones [4]. Our results are, in principle, supportive of recently published data demonstrating significant 
fluctuations in cyst fluid CEA upon repeat sampling of the same lesions over time, without association with malignant outcomes [24]. Understanding factors affecting the internal cyst milieu, and how this relates to cyst growth, requires further study.

Our goal is not to discourage surveillance for small pancreatic cysts but to shed light on the true clinical significance of cyst growth in small BD-IPMN lacking high-risk stigmata. We are aware of previous studies where baseline BD-IPMN cyst size alone failed to predict malignancy [24-26]. Similarly, the current study demonstrated that rapid cyst growth may not be an indicator of malignant transformation in small low risk BD-IPMNs and that the algorithm of management of BD-IPMN outlined by the 2012 ICG may need further examination. In some aspects, our results support the more recent AGA guidelines in adopting more than one high risk morphological feature (beyond size) as an indication for EUS-guided sampling or referral to surgery.

We also report that the rapid cyst growth tends to occur in older patients (70.8 vs. 64.1 years; $\mathrm{p}=0.03$ ). The relationship between age and malignant cyst outcome remains unclear based on the current literature. Symptomatic patients presumed to be related to cysts and cysts growing $>2 \mathrm{~mm} /$ year seem to undergo surgical resection more often than asymptomatic patients and slower growing cysts despite no significant difference on final surgical pathology according to at least one study [27]. In our study, cysts growing rapidly were found to be followed for a shorter duration. We believe that rapid cyst growth is caught early during surveillance in agreement with the 2017 revised International consensus guidelines (ICG) for the management of IPMNs that had diminished first follow up surveillance from 12 months to 6 months.

We recognize several limitations to our study, including the intermediate-term follow-up, retrospective design and tertiary center referral bias. In addition, the EUS procedures and the management of these patients were performed by expert endoscopists in the 
context of multidisciplinary programs; thus, the outcomes may not be generalizable to centers with less experience in this field. Furthermore, endoscopists were aware of the clinical history and this may have influenced their management and decision making. Cyst sizes in the current study were calculated by averaging the major and minor axis dimensions which is less accurate than threedimensional volume measurement of cystic lesions. Most lesions are not exactly spherical in shape, and determining the volume of an irregular lesion is difficult and impractical. Additionally, no central radiology review was constructed as part of the study which would have been impractical due to the large number of radiological exams involved (over 3000). We chose mean cyst growth rate percentage $(\mathrm{MGRP}) \geq 30 \% /$ year to be significant based on limited published evidence [4]. However, we provided a superior mathematical definition of rapid cyst growth accounting for baseline cyst size and time window of cyst surveillance. We also analyzed different thresholds for rapid cyst growth such as $\geq 2 \mathrm{~mm} /$ year which was recently adopted by the 2017 revised ICG. Finally, our sample size was smaller than that of other published studies but this related to our stringent inclusion criteria of only patients that underwent EUS evaluation plus FNA of cystic fluid for most patients (95.6\%). This stemmed from our knowledge of the limited diagnostic power of CT for pancreatic cyst and that EUS is the tool of choice for such lesions [28]. This has ensured that our studied population is truly comprised of only BD-IPMN and not other cysts of similar radiologic characteristics that could have undoubtedly been misclassified and included in previous BD-IPMN studies giving our results more credibility and accuracy. Given the above limitations, the validity of our findings should be confirmed in a prospective and longitudinal study.

In summary, we reported our experience in a diverse patient population with BD-IPMNs. Our study demonstrates that cyst growth is common over time in patients with BD-IPMNs undergoing surveillance imaging. Rapid cyst growth is not associated with known 
high-risk patient or cyst characteristics as well as advanced neoplasia on surgical pathology and thus unlikely to represent a worrisome feature.

\section{CONFLICT OF INTERREST}

Conflict of interest: None to report.

Financial disclosure: None to report. 


\section{References}

[1] Tanaka M, Fernández-Del Castillo C, Kamisawa T, et al. Revisions of international consensus Fukuoka guidelines for the management of IPMN of the pancreas. Pancreatology 2017;12: 738-753.

[2] Tanaka M, Chari S, Adsay V, et al. International consensus guidelines for management of intraductal papillary mucinous neoplasms and mucinous cystic neoplasms of the pancreas. Pancreatology 2006;6:17-32.

[3] Vege SS, Ziring B, Jain R, et al. American gastroenterological association institute guideline on the diagnosis and management of asymptomatic neoplastic pancreatic cysts. Gastroenterology 2015; 148:819-22; quize 12-3.

[4] Kang MJ, Jang JY, Kim SJ, et al. Cyst growth rate predicts malignancy in patients with branch duct intraductal papillary mucinous neoplasms. Clin Gastroenterol Hepatol 2011;9:87-93.

[5] Rautou PE, Lévy P, Vullierme MP, et al. Morphologic changes in branch duct intraductal papillary mucinous neoplasms of the pancreas: a midterm follow-up study. Clin Gastroenterol Hepatol 2008;6:807-14.

[6] Scheiman JM, Hwang JH, Moayyedi P. American gastroenterological association technical review on the diagnosis and management of asymptomatic neoplastic pancreatic cysts. Gastroenterology 2015;148:824-48.e22.

[7] Jang JY, Park T, Lee $S$, et al. Validation of international consensus guidelines for the resection of branch duct-type intraductal papillary mucinous neoplasms. Br J Surg 2014;101:686-92.

[8] Kim KW, Park SH, Pyo J, et al. Imaging features to distinguish malignant and benign branch-duct type intraductal papillary mucinous neoplasms of the pancreas: a meta-analysis. Ann Surg 2014;259:72-81.

[9] Brugge WR, Lewandrowski K, Lee-Lewandrowski E, et al. Diagnosis of pancreatic cystic neoplasms: a report of the cooperative pancreatic cyst study. Gastroenterology 2004;126:1330-6.

[10] Al-Haddad M, DeWitt J, Sherman S, et al. Performance characteristics of molecular (DNA) analysis for the diagnosis of mucinous pancreatic cysts. Gastrointest Endosc 2014;79:79-87.

[11] Flejou JF. [WHO Classification of digestive tumors: the fourth edition]. Ann Pathol 2011; 31(5 Suppl):S27-31.

[12] Khalid A, Zahid M, Finkelstein SD, et al. Pancreatic cyst fluid DNA analysis in evaluating pancreatic cysts: a report of the PANDA study. Gastrointest Endosc 2009;69:1095-102.

[13] Tanaka M, Fernández-del Castillo C, Adsay V, et al. International consensus guidelines 2012 for the management of IPMN and MCN of the pancreas. Pancreatology 2012;12:183-97.

[14] McGrath K. Management of incidental pancreatic cysts: which guidelines? Endosc Int Open 2017;5: E209-E211.

[15] Jacobson BC, Baron TH, Adler DG, et al. ASGE guideline: The role of endoscopy in the diagnosis and the management of cystic lesions and inflammatory fluid collections of the pancreas. Gastrointest Endosc 2005;61:363-70.

[16] Vege SS, Ziring B, Jain R, et al. American gastroenterological association institute guideline on the diagnosis and management of asymptomatic neoplastic pancreatic cysts. Gastroenterology 2015;148:819-22;quize12-3. 
[17] Woo SM, Ryu JK, Lee SH, et al. Branch duct intraductal papillary mucinous neoplasms in a retrospective series of 190 patients. Br J Surg 2009;96:405-11.

[18] Kwong WT, Lawson RD, Hunt G, et al. Rapid Growth Rates of Suspected Pancreatic Cyst Branch Duct Intraductal Papillary Mucinous Neoplasms Predict Malignancy. Dig Dis Sci 2015;60:2800-6.

[19] Salvia, R, Crippa S, Falconi M, et al. Branch-duct intraductal papillary mucinous neoplasms of the pancreas: to operate or not to operate? Gut 2007;56:1086-90.

[20] Tanno S, Nakano Y, Nishikawa T, et al. Natural history of branch duct intraductal papillary-mucinous neoplasms of the pancreas without mural nodules: long-term follow-up results. Gut 2008;57:339-43.

[21] Kobayashi G, Fujita N, Noda Y, et al. Mode of progression of intraductal papillary-mucinous tumor of the pancreas: analysis of patients with follow-up by EUS. J Gastroenterol 2005;40:744-51.

[22] Yamaguchi T, Baba T, Ishihara $T$, et al. Long-term follow-up of intraductal papillary mucinous neoplasm of the pancreas with ultrasonography. Clin Gastroenterol Hepatol 2005;3:1136-43.

[23] Maimone S, Agrawal D, Pollack MJ, et al. Variability in measurements of pancreatic cyst size among EUS, CT, and magnetic resonance imaging modalities. Gastrointest Endosc 2010;71:945-50.

[24] Schmidt CM, White PB, Waters JA, et al. Intraductal papillary mucinous neoplasms: predictors of malignant and invasive pathology. Ann Surg 2007;246:644-51; discussion 651-4.

[25] Wong, J, White PB, Waters JA, et al. High-grade dysplasia and adenocarcinoma are frequent in side-branch intraductal papillary mucinous neoplasm measuring less than $3 \mathrm{~cm}$ on endoscopic ultrasound. J Gastrointest Surg 2013;17:78-84;discussion $\mathrm{p}$ 84-5.

[26] Fritz S, Klauss M, Bergmann F, et al. Small (Sendai negative) branch-duct IPMNs: not harmless. Ann Surg 2012;256:313-20.

[27] Sahora K, Mino-Kenudson M, Brugge W, et al. Branch duct intraductal papillary mucinous neoplasms: does cyst size change the tip of the scale? A critical analysis of the revised international consensus guidelines in a large single-institutional series. Ann Surg 2013;258:466-75.

[28] Lu X, Zhang S, Ma C, et al. The diagnostic value of EUS in pancreatic cystic neoplasms compared with CT and MRI. Endosc Ultrasound 2015;4:324-9. 


\section{Legends}

Fig. 1 Flowchart

$B D$, branch duct; IPMN, intraductal papillary mucinous neoplasm; pts, patients, $M G R P$, mean growth rate percentage.

Figure 1. Flowchart. $B D$, branch duct; IPMN, intraductal papillary mucinous neoplasm; pts, patients, MGRP, mean growth rate percentage.

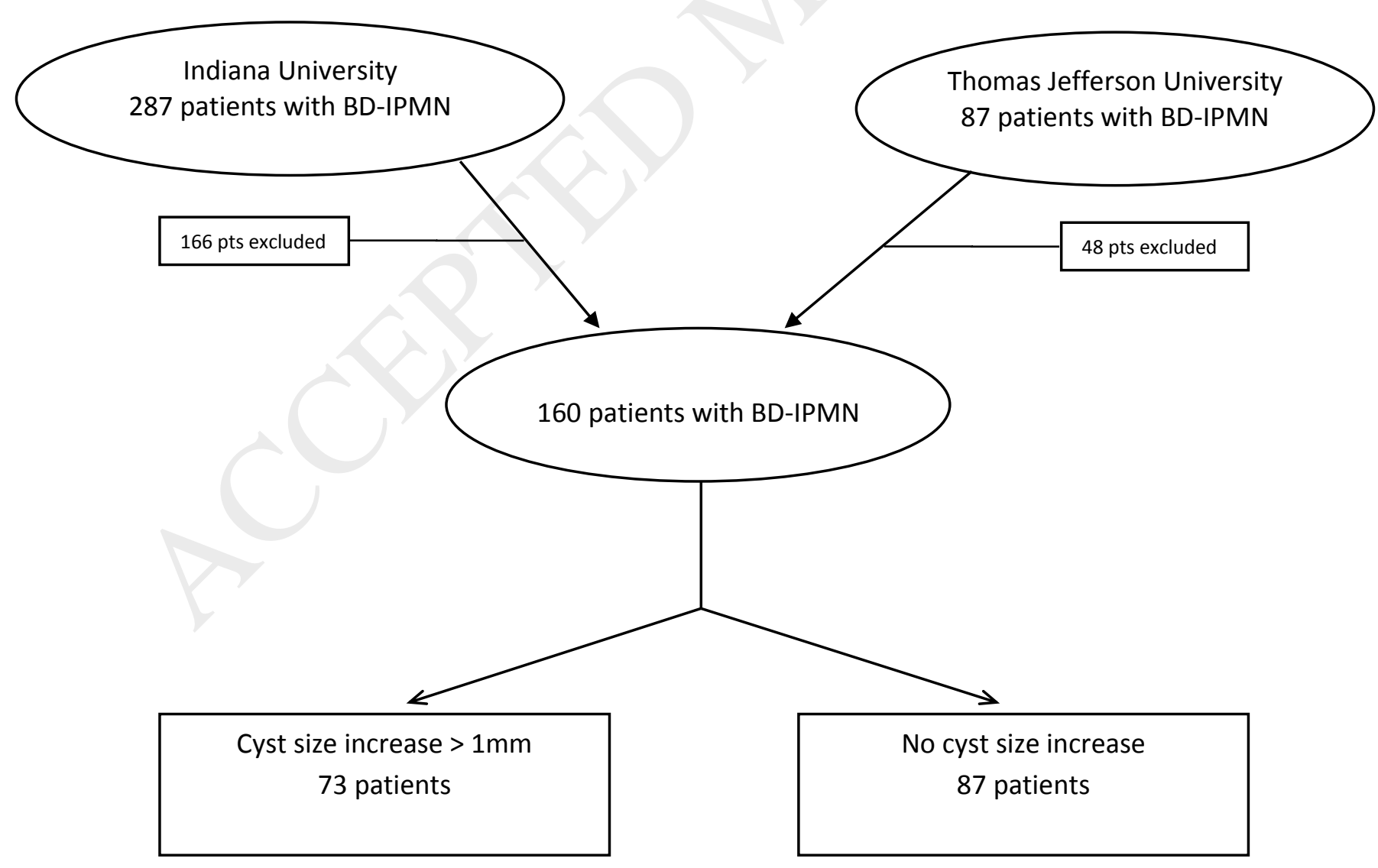




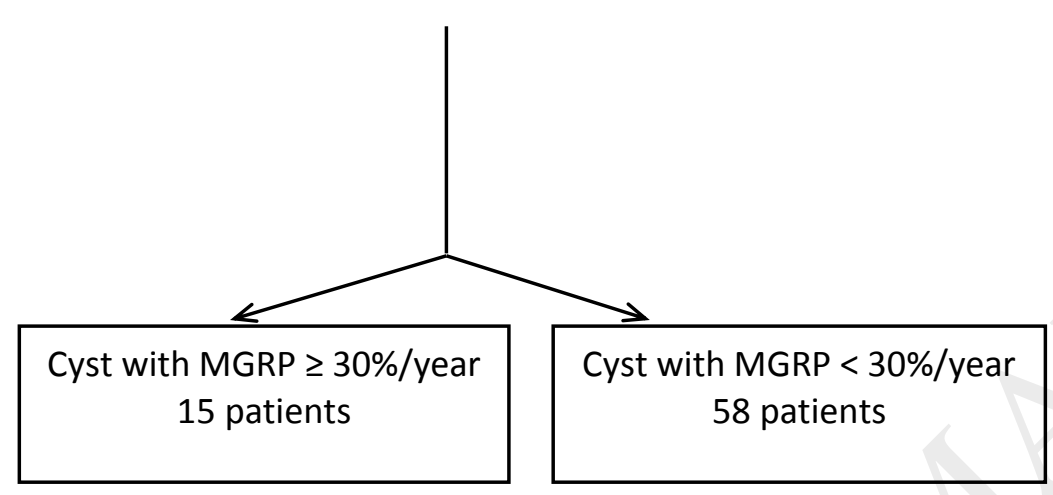


Fig. 2 Number of cysts categorized by growth rate.

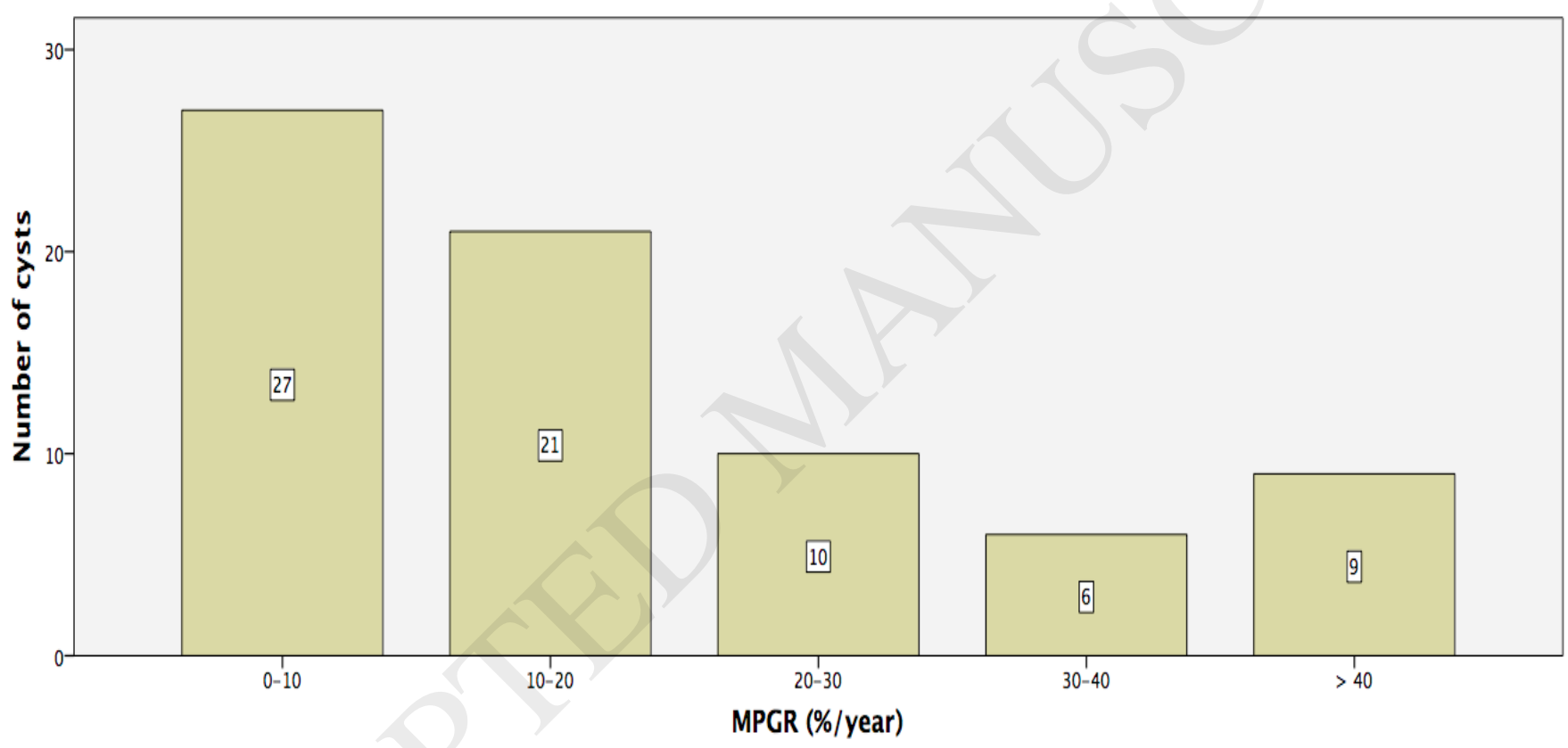


Fig. 3 Linear regression analysis of growth rate with respect to baseline cyst size.

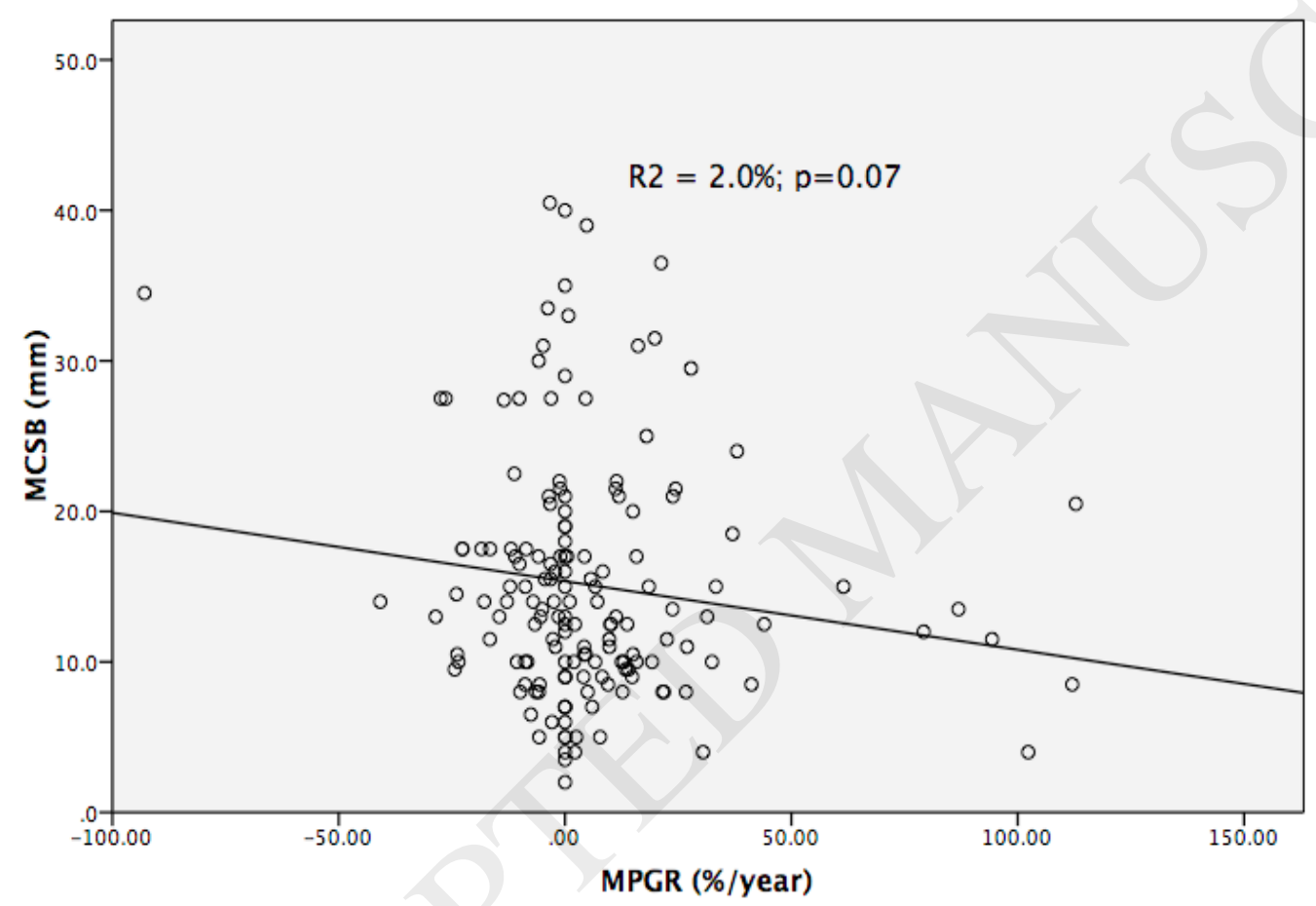


Table 1 Patients' characteristics.

\begin{tabular}{|l|l|}
\hline & $\mathrm{N}=160$ \\
\hline Mean age, years \pm SD & $64.6 \pm 12.0$ \\
\hline $\begin{array}{l}\text { Sex, no. (\%) } \\
\text { Male }\end{array}$ & $64(40 \%)$ \\
Female & $96(60 \%)$ \\
\hline Smoking (active or past use) & $29(20.7 \%)$ \\
\hline Alcohol use (active or past use) & $47(33.3 \%)$ \\
\hline Clinical symptoms related to BD-IPMN & \\
Acute pancreatitis & $30(20.8 \%)$ \\
Chronic pancreatitis & $6(4.2 \%)$ \\
Others symptoms & $24(16.7 \%)$ \\
Asymptomatic & $84(58.3 \%)$ \\
\hline Family history of pancreas cancer & $2(1.3 \%)$ \\
\hline
\end{tabular}


Table 2 Cysts' characteristics.

\begin{tabular}{|l|l|}
\hline & $\mathrm{N}(\%)$ \\
\hline Focality & \\
Unifocal & $139(86.9 \%)$ \\
Multifocal & $21(13.1 \%)$ \\
\hline Location & \\
Head & $67(41.9 \%)$ \\
Body & $48(30.0 \%)$ \\
Tail & $26(16.3 \%)$ \\
Uncinate process & $12(7.5 \%)$ \\
Neck & $7(4.4 \%)$ \\
\hline Septations & $73(45.6 \%)$ \\
\hline Nodule(s) & $5(3.1 \%)$ \\
\hline Mass component & $1(0.7 \%)$ \\
\hline Cyst fluid analysis & \\
Mean CEA level, ng/mL \pm SD & $2422.14 \pm 6207.87$ \\
Molecular analysis & $101(68.2 \%)$ \\
DNA quantity $\geq 40$ ng/ul & $8(7.9 \%)$ \\
DNA quality: good & $25(38.5 \%)$ \\
KRAS point mutation & $26(26 \%)$ \\
LOH $\geq 2$ allelic imbalance mutations & $8(8.2 \%)$ \\
\hline Surgical pathology & $18(11.3 \%)$ \\
Low grade dysplasia & $15(83.3 \%)$ \\
High grade dysplasia & $1(5.6 \%)$ \\
Invasive cancer & $2(11.1 \%)$ \\
\hline LOH, Loss of heterozygosity. & \\
\hline
\end{tabular}


Table 3 Cysts' size, growth rate, and growth rate percentage.

\begin{tabular}{|l|l|}
\hline MCSB, MGR, MGRP & Mean \pm SD \\
\hline MCSB, mm \pm SD & $15.10 \pm 8.03$ \\
\hline MGR, mm/year \pm SD & $0.58 \pm 4.33$ \\
\hline MGRP, \%/year \pm SD & $5.68 \pm 24.89$ \\
\hline & \\
\hline Cyst size variation & $\mathbf{N}(\%)$ \\
\hline Increased & $73(45.6 \%)$ \\
\hline MGR $\geq 2 \mathrm{~mm} /$ year & $31(19.4 \%)$ \\
\hline MGR $\geq 5 \mathrm{~mm} /$ year & $16(10.0 \%)$ \\
\hline MGRP $\geq 30 \% /$ year & $15(9.4 \%)$ \\
\hline Stable or decreased & $87(54.4 \%)$ \\
\hline
\end{tabular}

MCSB, Mean cyst size at baseline; MGR, Mean cyst growth rate; MGRP, Mean growth rate percentage 
Table 4. Cyst characteristics and surgical status according to follow up duration.

\begin{tabular}{|c|c|c|c|}
\hline & \multicolumn{3}{|c|}{ Follow up Duration } \\
\hline & $\begin{array}{l}<27 \text { months } \\
N=80\end{array}$ & $\begin{array}{l}\geq 27 \text { months } \\
\mathrm{N}=80\end{array}$ & $P$ value \\
\hline Surgery performed & $12(15.0 \%)$ & $6(7.5 \%)$ & 0.13 \\
\hline Cyst size increased & $38(47.5 \%)$ & $35(43.8 \%)$ & 0.63 \\
\hline MGRP $\geq 30 \% /$ year & $13(16.3 \%)$ & $2(2.5 \%)$ & 0.03 \\
\hline MGR $\geq 2 \mathrm{~mm} /$ year & $23(28.8 \%)$ & $8(10.0 \%)$ & 0.03 \\
\hline CEA level > $192 \mathrm{ng} / \mathrm{ml}$ & $26(53.1 \%)$ & $21(56.8 \%)$ & 0.73 \\
\hline DNA quantity $\geq 40 \mathrm{ng} / \mathrm{ul}$ & $7(12.7 \%)$ & $1(2.2 \%)$ & 0.05 \\
\hline DNA quality: good & $16(50.0 \%)$ & $9(27.3 \%)$ & 0.06 \\
\hline KRAS point mutation & $12(22.2 \%)$ & $14(30.4 \%)$ & 0.35 \\
\hline LOH $\geq 2$ allelic imbalance mutations & $4(7.7 \%)$ & $4(8.9 \%)$ & 0.83 \\
\hline
\end{tabular}


Table 5 Correlation between MGR, MGRP and Patients' and Cysts' Characteristics.

\begin{tabular}{|c|c|c|c|c|c|c|}
\hline & $\begin{array}{l}\text { MGR <2mm/year } \\
(\mathrm{N}=135)\end{array}$ & $\begin{array}{l}\text { MGR } \geq 2 \mathrm{~mm} / \text { year } \\
(\mathrm{N}=25)\end{array}$ & $P$ value & $\begin{array}{l}\text { MGRP < 30\%/year } \\
(\mathrm{N}=145)\end{array}$ & $\begin{array}{l}\text { MGRP } \geq 30 \% / \text { year } \\
(\mathrm{N}=15)\end{array}$ & $P$ value \\
\hline \multicolumn{7}{|l|}{ Patient characteristics } \\
\hline Male & 45 (34.9\%) & $19(61.3 \%)$ & 0.007 & 56 (38.6\%) & $8(53.3 \%)$ & 0.27 \\
\hline Female & $84(65.1 \%)$ & $12(38.7 \%)$ & & 89 (61.4\%) & $7(46.7 \%)$ & \\
\hline Smoking & $22(19.3 \%)$ & $7(26.9 \%)$ & 0.37 & $26(20.3 \%)$ & $3(25.0 \%)$ & 0.70 \\
\hline Alcohol use & $37(32.2 \%)$ & 10 (38.5\%) & 0.54 & 44 (34.1\%) & $3(25.0 \%)$ & 0.52 \\
\hline Clinical symptoms related to BD-IPMN & $47(39.8 \%)$ & $13(50.0 \%)$ & 0.34 & 54 (59.1\%) & $6(50.0 \%)$ & 0.54 \\
\hline Family history of pancreas cancer & $9(9.5 \%)$ & 0 & 0.17 & $9(8.9 \%)$ & 0 & 0.08 \\
\hline Mean age (years) & 64.2 & 66.5 & 0.35 & 64.0 & 70.8 & 0.03 \\
\hline & 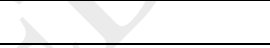 & & & & & \\
\hline \multicolumn{7}{|l|}{ Cyst characteristics } \\
\hline Unifocal & $110(85.3 \%)$ & $29(93.5 \%)$ & 0.22 & $125(86.2 \%)$ & $14(93.3 \%)$ & 0.44 \\
\hline Septations & $58(45.0 \%)$ & $15(48.4 \%)$ & 0.73 & $66(45.5 \%)$ & $7(46.7 \%)$ & 0.93 \\
\hline Nodule(s) & $3(2.9 \%)$ & $2(10.5 \%)$ & 0.13 & $4(3.7 \%)$ & $1(8.3 \%)$ & 0.44 \\
\hline Mass component & 0 & $1(3.6 \%)$ & 0.04 & 0 & $1(7.7 \%)$ & 0.001 \\
\hline Cyst fluid analysis & & & & & & \\
\hline $\mathrm{CEA}>192 \mathrm{ng} / \mathrm{mL}$ & $32(51.6 \%)$ & $15(62.5 \%)$ & 0.36 & $41(53.2 \%)$ & $6(66.7 \%)$ & 0.44 \\
\hline Molecular analysis & & & & & & \\
\hline DNA quantity $\geq 40 \mathrm{ng} / \mu \mathrm{l}$ & $5(6.3 \%)$ & $3(13.6 \%)$ & 0.26 & $6(6.5 \%)$ & $2(25.0 \%)$ & 0.06 \\
\hline Kras point mutation & $20(25.6 \%)$ & $6(27.3 \%)$ & 0.88 & $24(26.1 \%)$ & $2(25.0 \%)$ & 0.95 \\
\hline $\mathrm{LOH} \geq 2$ & $6(7.8 \%)$ & $2(10.0 \%)$ & 0.75 & $6(6.7 \%)$ & $2(28.6 \%)$ & 0.05 \\
\hline Surgical resection performed & $8(6.2 \%)$ & $10(32.3 \%)$ & 0.00 & 15 (10.3\%) & $3(20.0 \%)$ & 0.26 \\
\hline Benign/malignant & $7 / 1$ & $8 / 2$ & 0.65 & $13 / 2$ & $2 / 1$ & 0.40 \\
\hline
\end{tabular}

MGR, Mean cyst growth rate; MGRP, Mean growth rate percentage; LOH, loss of heterozygosity; CEA, carcinoembryonic antigen 
Table 6 Summary of published studies evaluating the correlation between cyst size/growth and malignant outcomes.

\begin{tabular}{|c|c|c|c|c|c|c|c|c|c|}
\hline \multicolumn{2}{|c|}{ Author } & Rautou et al. $^{5}$ & Woo et al. ${ }^{17}$ & \multicolumn{2}{|c|}{ Kang et al. ${ }^{4}$} & \multicolumn{2}{|c|}{ Kwong et al. ${ }^{18}$} & \multicolumn{2}{|c|}{ Current } \\
\hline \multicolumn{2}{|c|}{ Year of publication } & 2008 & 2009 & \multicolumn{2}{|c|}{2011} & \multicolumn{2}{|c|}{2015} & \multicolumn{2}{|c|}{2017} \\
\hline \multicolumn{2}{|c|}{ Country } & France & South Korea & \multicolumn{2}{|c|}{ South Korea } & \multicolumn{2}{|c|}{ U.S. $\times 4$} & \multicolumn{2}{|c|}{ U.S. x 2} \\
\hline \multicolumn{2}{|c|}{ Type of study } & Retrospective & Retrospective & \multicolumn{2}{|c|}{ Retrospective } & \multicolumn{2}{|c|}{ Retrospective } & \multicolumn{2}{|c|}{ Retrospective } \\
\hline \multicolumn{2}{|c|}{ Period of time } & 1999-2005 & $1998-2005$ & \multicolumn{2}{|c|}{$2000-2009$} & \multicolumn{2}{|c|}{$2002-2011$} & \multicolumn{2}{|c|}{$1996-2013$} \\
\hline \multicolumn{2}{|c|}{ Center(s) } & Single center & Single center & Sing & le center & $\mathrm{Mul}$ & ticenter & Mul & Iticenter \\
\hline Number & patients & 121 & 190 & 201 & & 284 & & 160 & \\
\hline Male/Fer & & $32 / 89$ & $111 / 79$ & 111 & 90 & 123 & $/ 161$ & $64 / 9$ & \\
\hline Mean ag & (years) & 63 & 63 & 62. & & 67 & & 64.6 & \\
\hline Surveillar & & 104 & 105 & 166 & & 272 & & 150 & \\
\hline Surgery & Benign & 17 & 71 & 35 & 27 & 12 & 3 & 18 & 15 \\
\hline & Malignant & 4 & 14 & & 8 & & 9 & & 3 \\
\hline $\begin{array}{l}\text { Follow-u } \\
\text { Median } \\
\text { Range } \\
\end{array}$ & (months) & $\begin{array}{l}33 \\
12-94 \\
\end{array}$ & $\begin{array}{l}25 \\
6-86 \\
\end{array}$ & $\begin{array}{l}27 . \\
3.2 \\
\end{array}$ & 109.5 & $\begin{array}{l}56 \\
36-\end{array}$ & & $\begin{array}{l}27.4 \\
12-1 \\
\end{array}$ & $\begin{array}{l}4 \\
114.5 \\
\end{array}$ \\
\hline Imaging & & CT, MRCP, EUS & CT, MRCP, EUS, ERCP & $\mathrm{CT}$, & MRCP, EUS, ERCP & $\mathrm{CT}$, & MRCP, EUS & $\mathrm{CT}, \mathrm{I}$ & MRCP, EUS +/- FNA \\
\hline Standard & or diagnosis & $\begin{array}{l}\text { First } 3 \text { years of f/up: } \\
\text { Alternated imaging every } 8 \\
\text { months } \\
\text { After } 3 \text { years: yearly }\end{array}$ & $>2$ imaging studies & $\begin{array}{l}\text { CT } \\
\text { Eve } \\
\text { The }\end{array}$ & $\begin{array}{l}\text { 3-6 months-first year } \\
\text { n every } 9-12 \text { months }\end{array}$ & & $\begin{array}{l}\text { least } 2 \text { cross-sectional } \\
\text { ging } 6 \text { months apart }\end{array}$ & & $\begin{array}{l}\text { least } 2 \text { cross-sectional } \\
\text { ging; minimal of } 6 \\
\text { nths of surveillance }\end{array}$ \\
\hline $\begin{array}{l}\text { Cyst size } \\
\text { and minc } \\
\text { axial ima }\end{array}$ & $\begin{array}{l}\text { axerage of major } \\
\text { axis diameter on } \\
\text { s) }\end{array}$ & Yes & Yes & Yes & & Yes & & Yes & \\
\hline Criteria & & $\begin{array}{l}\text { Increase in cyst size }>5 \\
\mathrm{~mm} \text { (between diagnosis }\end{array}$ & Increase in cyst size $\geq 20 \%$ & $\begin{array}{l}\text { Cys } \\
2 \mathrm{~m}\end{array}$ & $\begin{array}{l}\text { growth rate } \geq \\
\text { n/year }\end{array}$ & $\begin{array}{l}\text { Cys } \\
2 \mathrm{mr}\end{array}$ & $\begin{array}{l}\text { growth rate } \geq \\
\text { n/year }\end{array}$ & MGI & $\mathrm{RP} \geq 30 \%$ \\
\hline & & and end of f/up period) & & & & Tot & al growth $\geq 10 \mathrm{~mm}$ & & \\
\hline & & & & & & $\% \mathrm{~g}$ & rowth > $40 \%$ & & \\
\hline Conclusic & & $\begin{array}{l}\text { Cyst size increase by more } \\
\text { than } 5 \mathrm{~mm} \text { during the }\end{array}$ & $\begin{array}{l}\text { Not a reliable predictor of } \\
\text { malignancy in the absence }\end{array}$ & $\begin{array}{l}\text { Pre } \\
\text { mal }\end{array}$ & $\begin{array}{l}\text { licts high risk of } \\
\text { gnancy }\end{array}$ & $\begin{array}{l}\text { Pre } \\
\text { mal }\end{array}$ & $\begin{array}{l}\text { dicts high risk of } \\
\text { ignancy }\end{array}$ & & $\begin{array}{l}\text { growth is common } \\
r \text { time }\end{array}$ \\
\hline & & follow-up suggested & of other suspicious & & & Se 7 & $8 \mathrm{Sp} 90$ A 88 & Rapi & id cyst growth not \\
\hline & & malignant progression & features on imaging & & & Se 1 & $00 \mathrm{Sp} 95$ A 95 & & ociated with high risk \\
\hline & & & & & & Se 7 & $8 \mathrm{Sp} 84 \mathrm{~A} 84$ & char & $\begin{array}{l}\text { racteristics, and } \\
\text { anced neoplasia on } \\
\text { gical pathology }\end{array}$ \\
\hline
\end{tabular}

